Journal of Mathematics and Statistics 7 (3): 239-248, 2011

ISSN 1549-3644

(C) 2011 Science Publications

\title{
Application of Theories of Complexity and Chaos to Economic Misgovernance
}

\author{
Partha Gangopadhyay, Nasser Elkanj and Mustafa A. Rahman \\ School of Economics and Finance, University of Western Sydney, \\ Locked Bag 1797, Penrith South DC, NSW 1797, Australia
}

\begin{abstract}
Problem statement: In this study we develop a comprehensive model involving local taxes, intergovernmental transfers and bureaucratic corruption to characterize a fiscal equilibrium in order to explain the provision of local (public) expenditure in developing nations. The main goal of the research is to explain economic misgovernance as an equilibrium phenomenon, which is therefore expected to persist over time despite serious economic and social costs. Approach: We develop an interactive model of fiscal gaming to understand economic misgovernance in the context of game theory. Resutls: It is constructively argued that the proposed fiscal game is beset with multiple equilibria and the consequent indeterminacy. The possibility of unstable equilibria, or an absence of pure-strategy equilibrium renders the system highly fragile. We also demonstrate the possibility of serious bifurcations of a stable fiscal equilibrium that loses stability with changes in values of relevant parameters. We extend this model further to argue how the chaotic behavior and complexities can characterize the dynamics of decision-making in this present context. Conclusion: The emergence of chaos can undermine the efficiency and predictability of the equilibrium of the proposed fiscal game, which can in turn seriously impinge on the quality of local goods in developing nations. We argue that an understanding of the fragility and complexity of local government system is essential for policy makers for achieving a sustainable local government system in developing nations.
\end{abstract}

Key words: Local expenditure, Li-York theorem, nash equilibrium, multiple equilibria, bifurcation chaos, developing nations, local government system, highly fragile, multiple equilibria, developed countries

\section{INTRODUCTION}

In developing countries, as in developed countries, local governments typically respond toincentives and operate within constraints wherefrom the equilibrium local expenditure is derived. It is a moot point whether local expenditures in developing nations are economically efficient and politically acceptable. For being efficient, local governments must be entrusted with significant role in raising revenues and allocating its expenditure and be given sufficient incentives to act in a responsible and efficient way. There is mounting evidence that local governance has faced problems in developing nations in recent years. As an example, the picture of urban local governance in India has not been pretty: the basic minimum of local goods was not offered to $300 \mathrm{~m}$ people while the shortfall, or gap, in the provision of local goods against the backdrop of the norm is also amazingly high (Gangopadhyay and Nath, 2001a; 2001b). It is imperative that the profession offers explanation and understanding of this type of serious under-provision of local goods below the (recommended) absolute minimum. The current work is an attempt towards this collective goal.

It is widely held that local governments in the developing world have little autonomy in raising revenues and little flexibility in determining local tax rates (Bird, 1993). This lack of autonomy and flexibility is believed to have deleterious consequences for the standard of livings of millions (Bird et el., 1995; Bird 1995). At the same time, it is well understood that unconditional grants and limited conditionality of transfers from central governments usually lead to fungibility of money, cannibalization of resources and diversion of funds for non-local use and rampant corruption (Bird and Wallich, 1992; Shah, 1991). Thus the fiscal outcome in developing nations is a product of institutional and behavioral peculiarities that offer specific incentives and create relevant constraints for central governments and local governments. In what follows is a simple model that characterizes a fiscal equilibrium in the context of a set of institutional and

Corresponding Author: Partha Gangopadhyay, University of Western Sydney, Locked Bag 1797, Penrith South DC, NSW 1797, Australia 
behavioral peculiarities that capture the typical features of the landscape of local governments in developing nations (Fig. 1 and 2).

One of the main characteristics local governance in developing nations is the little autonomy that local governments have in determining local taxes, as opposed to their counterparts from the developed world.

Typically, in developing nations, central and state governments transfer resources to local governments for which local governments have little accountability. Local governments have more accountability towards tied grants-in-aid and also for resources they raise locally. This lack of accountability paves the way for corrupt behavior by local governments in developing nations. The special institutional structures of local governments in developing nations have been inherited from the colonial rubrics of these nations in which national/state governments offer finances to municipalities (local governments) for supplying local goods and local infrastructure. Local governments traditionally levy low tax rates on local residents and businesses. Given the current institutional milieu we develop a simple game to establish that the inadequate supply of local goods and infrastructures in urban areas of developing nations is an equilibrium phenomenon.

We argue that the source of problems with (urban) local governance in developing nations is an incorrect tax scheme that is propelled by the electoral motive of local governments. This study, hence, calls forth reforms of property taxes, implementation of property rights and introduction Tiebout-type of competitive forces in the provision of local goods in developing nations. We thereby highlight how incorrect designs of transfers and a lack of true accountability can cause serious distortions in the provision and quality of local goods in developing nations. We construct a model in which local governments raise little resources locally. Local governments are more accountable to these resources raised by local taxes (some kind of fly study effect). Most of the local governments' expenditures are financed by central and state government transferssome of which are tied and some are untied. Local governments are actuated by electoral motives while higher level of governments-central and state governments - are more concerned with the welfare of residents in determining their transfers to local governments. On the basis of these ideas we develop a simple game of local governance in developing nations and characterize the Nash equilibria of the proposed fiscal game. The plan of the study is the following: we offer a simple model to explain the game and the relevant Nash equilibria and their stability properties. We then explain how chaotic regimes can characterize fiscal reforms and then conclude. $\theta$

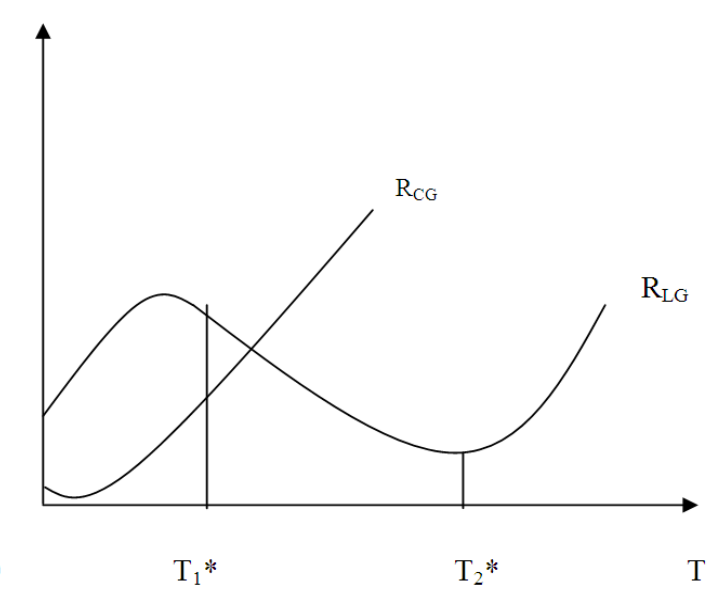

Fig. 1: Reaction functions of the layers

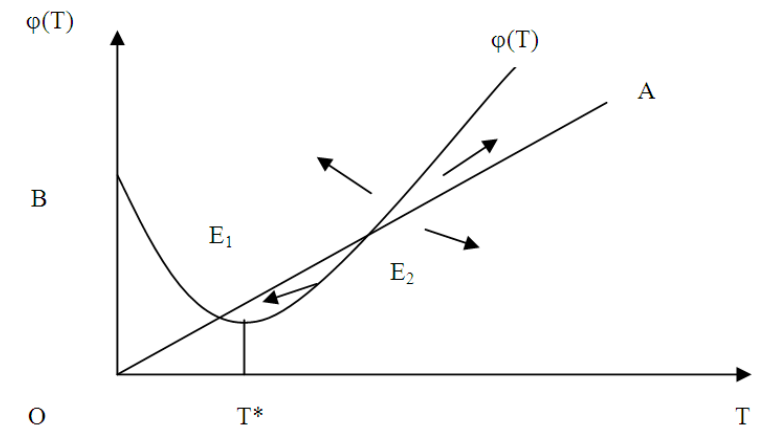

Fig. 2: The fixed point problem and multiple equalibria

The model: A typical local government has two levels of accountability. The first level of accountability is to local taxpayers for the use of resources mobilized from their residents. The second level of accountability is to the central government for the appropriate use of transfers. We posit that a typical local government is more accountable to the local residents than to the central government. To make our model tractable, we assume that local governments cannot divert resources that it collects from local residents through local taxes while it is possible to divert intergovernmental transfers for other purposes. Thus, the corruption in our model entails a simple diversion of untied transfers. This is a well-known feature of developing nations that has prompted perceptible observers to recommend matching and tied grants to replace transfers (Bird et el., 1995). The reality is that most transfers are still untied (Gangopadhyay and Nath, 2001a; 2001b). Another facet of local governance in developing nations is little flexibility that local governments enjoy in setting taxes. For modeling purpose, we assume that the 
local taxes are set by the central government while the revenues are collected and utilized by local governments.

In the above scenario the fiscal game unfolds in the following fashion: the central government sets the local taxes to maximize its payoff/welfare given the diversion of funds by the local government. The local government chooses the level of corruption (diversion of funds) to maximize its payoff/welfare given the local taxes and intergovernmental transfers. The resultant Nash equilibrium entails the combination of taxes and diversion of funds that are self-confirming.

Local government: The payoff function of an incumbent local government is as follows:

$E^{R}=\alpha \theta(Y-T)-c \theta$

Where:

a = Probability of re-election of the incumbent local government

$\mathrm{Y}=$ Total funds available to the local government

$\mathrm{T}=$ Tax revenue collected by the local government

$(\mathrm{Y}-\mathrm{T})=$ Untied fund that the local government can divert

$\theta \quad=$ Proportion of untied funds that the local government diverts

$\mathrm{c} \theta=$ Political cost, or non-pecuniary, costs associated with diverting funds

Note that $\theta$ is the choice variable of the local government. It is further postulated that an incumbent can divert funds for personal use that is not raised locally. This is an extreme version of the celebrated flystudy effect. We also postulate that $\alpha$ is given by:

$\alpha=\alpha_{1}(1-\theta) \mathrm{Y}-\alpha_{2} \mathrm{~T}$

The probability of re-election of the incumbent local government is positively related to the utilized fund, (1- $\theta) \mathrm{Y}$, for local goods and negatively related to the resources raised locally, T, while $\alpha_{1}$ and $\alpha_{2}>0$. Hence the expected payoff of the incumbent local government is given as:

$E^{R}=\left[\alpha_{1}(1-\theta) Y-\alpha_{2} T\right] \theta(Y-T)-c \theta$

The first order condition to maximize $\mathrm{E}^{\mathrm{R}}$ with respect to the choice variable $\theta$ is gives the reaction function of the local government:

$\theta=1 / 2-\left[c+a_{2} T(Y-T)\right] /\left[2 a_{1} Y(Y-T)\right]$

The second order condition requires: $\left(d^{2} E^{R} / d \theta^{2}\right)=2 Y(T-Y) \alpha_{1}<0$

The second order condition is satisfied since $\mathrm{Y}>\mathrm{T}$. The slope of the reaction function of the incumbent local government is given by:

$[d T / d \theta]_{L G}=\left[(Y-T)\left(a_{2} Y-2 a_{2}\right)-\left(c+a_{2} T(Y-T)\right] /\left[Y(Y-T)^{2}\right](4 c)\right.$

Note that $[\mathrm{dT} / \mathrm{d} \theta]_{\mathrm{LG}}>0$ if:

$\mathrm{Z}=(\mathrm{Y}-\mathrm{T})\left(\mathrm{a}_{2} \mathrm{Y}-2 \mathrm{a}_{2}\right)-\left[\mathrm{c}+\mathrm{a}_{2} \mathrm{~T}(\mathrm{Y}-\mathrm{T})\right]>0$

Define $\mathrm{m}_{1}=\mathrm{Y}\left(\mathrm{a}_{2} \mathrm{Y}-2 \mathrm{a}_{2}-\mathrm{c}\right)$

$\mathrm{m}_{2}=\left(\mathrm{a}_{1}+\mathrm{a}_{2}\right) \mathrm{Y}-2 \mathrm{a}_{2}$

Thus $\mathrm{T}$ has two critical values $\mathrm{T}_{1} *$ and $\mathrm{T}_{2} *$ given by:

$\left.\mathrm{T}_{1} *=\left(\mathrm{m}_{2}-\operatorname{sqrt}\left\{\mathrm{m}_{2}^{2}-4 \mathrm{~m}_{1} \mathrm{a}_{2}\right)\right\}\right) /\left(2 \mathrm{a}_{2}\right)$

$\left.\mathrm{T}_{2}{ }^{*}=\left(\mathrm{m}_{2}+\operatorname{sqrt}\left\{\mathrm{m}_{2}{ }^{2}-4 \mathrm{~m}_{1} \mathrm{a}_{2}\right)\right\}\right) /\left(2 \mathrm{a}_{2}\right)$

$[\mathrm{dT} / \mathrm{d} \theta]_{\mathrm{LG}}>0$ if $\mathrm{T}<\mathrm{T}_{1} *$ or $\mathrm{T}>\mathrm{T}_{2}{ }^{*}$

$[\mathrm{dT} / \mathrm{d} \theta]_{\mathrm{LG}}<0$ if $\mathrm{T}_{1} *<\mathrm{T}<\mathrm{T}_{2} *$

Thus, one can draw the reaction function of the local government as $\mathrm{R}_{\mathrm{LG}}$ in Diagram 1: the reaction function has a positive slope till $\mathrm{T}_{1} *$. Thus, the reaction function of the local government displays strategic complementarity for $0<\mathrm{T}<\mathrm{T}_{1} *$. The reaction function of the local government assumes a negative slope, displaying strategic substitutability, for $\mathrm{T}_{1} *<\mathrm{T}<\mathrm{T}_{2} *$. For $\mathrm{T}>\mathrm{T}_{2}{ }^{*}$, the reaction function has a positive slope that reflects strategic complementarity. We now examine the reaction function of thecentral government.

Central government: We posit that the central government intends to improve the welfare of citizens. The welfare of a typical citizen $\mathrm{U}(\mathrm{x})$ is assumed to be the following:

$\mathrm{U}(\mathrm{x})=\mathrm{x}(\mathrm{K}-\mathrm{T})$

Where:

$\mathrm{x}=$ Consumption of local goods

$\mathrm{T}=$ Tax burden of citizens and $\mathrm{K}$ is their income such that:

$\mathrm{x}=(1-\theta)(\mathrm{Y}-\mathrm{T})+\mathrm{T}=\mathrm{Y}-(\mathrm{Y}-\mathrm{T}) \boldsymbol{\theta}$

The central government has an opportunity cost of $\lambda$ for each dollar of (Y-T) that it transfers to the local 
government. For tractability, we set $\lambda=0$ without losing any analytical bite. Thus the first order condition to maximize (6) with respect to T, given Eq. 7, yields the reaction function of the central government:

$\mathrm{T}=[\mathrm{K} \theta-(1-\theta) \mathrm{Y}] /[2 \theta]$

The second order condition yields:

$$
\left(\mathrm{d}^{2} \mathrm{U} / \mathrm{dT}^{2}\right)=-2 \theta<0
$$

The slope of the reaction function of the central government $(\mathrm{dT} / \mathrm{d} \theta)_{\mathrm{CG}}$ :

$$
(\mathrm{dT} / \mathrm{d} \theta)_{\mathrm{CG}}=\mathrm{Y} /\left(2 \theta^{2}\right)>0
$$

We draw the reaction function of the central government as $\mathrm{R}_{\mathrm{CG}}$ in Diagram 1, which shows that for the central government $\mathrm{T}$ and $\theta$ are strategic complements.

Nash equilibrium configurations: The Nash equilibrium of the proposed game is given by the values of $(T, \theta)$ that simultaneously satisfy Eq. $4 \mathrm{a}$ and $8 \mathrm{a}$. From Eq. 8c we know that the slope of the reaction function of the central government $(\mathrm{dT} / \mathrm{d} \theta)_{\mathrm{CG}}>0$. From (5d) and (5d') we know that the reaction function of the local government is non-monotonic, which may create several cases of multiple equilibria. Gangopadhyay (2007) for further analytical and technical foundation. We provide a qualitative exposition of the Nash equilibrium in Diagram 1: the Nash equilibria are given by the points of intersection between $\mathrm{RC}_{\mathrm{G}}$ and $\mathrm{R}_{\mathrm{LG}}$ in the diagram.

Lemma 1: The equilibrium of the proposed fiscal game is mathematically equivalent to the following fixed point problem:

$$
\mathrm{T}=\phi(\mathrm{T})
$$

Where $\phi(T)$ is a continuous function of $\mathrm{T}$ and given by:

$$
\begin{aligned}
& \phi(T)=\left[2 \mathrm{a}_{2} \mathrm{Y}^{2}\right] /\left[2 \mathrm{a}_{1} \mathrm{Y}\right]-\left[\mathrm{r}_{0}-\mathrm{r}_{1} \mathrm{~T}+2 \mathrm{r}_{2} \mathrm{~T}^{2}\right] /\left[2 \mathrm{a}_{1} \mathrm{Y}\right] \\
& \text { wherer }_{0}=2\left(c+\mathrm{a}_{2}\right)+(\mathrm{K}+\mathrm{Y})+\mathrm{Y}(\mathrm{K}+\mathrm{Y})+\mathrm{a}_{1} \mathrm{YK}+\mathrm{a}_{1} \mathrm{Y}^{2} \\
& \mathrm{r}_{1}=4\left(\mathrm{c}+\mathrm{a}_{2}\right)+(\mathrm{K}+\mathrm{Y})+\mathrm{Y}+2 \mathrm{a}_{1} \mathrm{Y}+\mathrm{a}_{1} \mathrm{YK}+\mathrm{a}_{1} \mathrm{Y}^{2} \\
& \mathrm{r}_{3}=\left(1+2 \mathrm{a}_{1} \mathrm{Y}\right)
\end{aligned}
$$

Proof: The Nash equilibrium requires $\mathrm{T}$ and $\theta$ be the mutual best responses. From the reaction function of the central government we express as $\theta$ :

$\theta=1 /[\mathrm{K}+\mathrm{Y}-2 \mathrm{~T}]$

From the reaction function of the local government we express $\theta$ :

$\theta=(1 / 2)-\left[c+a_{2} T(Y-T)\right] /\left[a_{1} Y(Y-T)\right]$

From (9f) and (9f') we get rid off $\theta$ to arrive at (9b)-(9d). QED.

Lemma 2: The function $\phi(T)$ is $U$-shaped. For $\mathrm{T}=0$, $\phi(\mathrm{T})=\mathrm{a}_{2} /\left(\mathrm{a}_{1} \mathrm{Y}\right)$ and $\phi(\mathrm{T})$ declines as $\mathrm{T}$ increases till $\mathrm{T}^{2} \mathrm{~T}^{*}$. At $\mathrm{T}^{*}=\left(\mathrm{r}_{1}+2 \mathrm{a}_{1} \mathrm{Y}\right) /\left(4 \mathrm{r}_{2}\right) \quad \phi(\mathrm{T})$ reaches the minimum. For $\mathrm{T}>\mathrm{T}^{*}$, the function $\phi(\mathrm{T})$ is increasing in T. We draw the function $\phi(T)$ in Diagram 2. Diagram 2 shows the existence of 2 equilibria $E_{1}$ and $E_{2}$. Note that $\mathrm{E}_{2}$ is always unstable while $\mathrm{E}_{1}$ is stable if $\left|\phi^{\prime}(\mathrm{T})\right|<1$.

Proof: Differentiating $\phi(\mathrm{T})$ with respect to T yields the result. QED.

Note: $\mathrm{OA}$ is the $45^{\circ}$ line, $\mathrm{OB}=\mathrm{a}_{2} \mathrm{Y} / \mathrm{a}_{1}, \mathrm{E}_{1}$ and $\mathrm{E}_{2}$ are the two fixed points, $E_{2}$ is always unstable. $E_{1}$ is stable if condition (10a) holds.

Lemma 3: The stability of equilibrium $E_{1}$ requires that the equilibrium value of $\mathrm{T}$, say $\mathrm{T}^{\mathrm{E}}$, must lie above a critical value:

$\mathrm{T}^{\mathrm{E}}>\left[\mathrm{r}_{1}+2 \mathrm{a}_{1} \mathrm{Y}\right] /\left[4 \mathrm{r}_{2}\right]$

The equilibrium $\mathrm{E}_{1}$ is unstable if

$\mathrm{T}^{\mathrm{E}}<\left[\mathrm{r}_{1}+2 \mathrm{a}_{1} \mathrm{Y}\right] /\left[4 \mathrm{r}_{2}\right]$

Proof: The condition for stability of $E_{1}$ is $\left|\phi^{\prime}(T)\right|<1$. Differentiating $\phi(\mathrm{T})$ with respect to $\mathrm{T}$ and setting $\phi^{\prime}(\mathrm{T})<1$ yields (10a). (10b) is obtained by reversing inequality (10a). QED.

Observation 1: There exists no pure-strategy Nash equilibrium if the following condition is satisfied:

$\phi\left(\mathrm{T}^{*}\right)>\mathrm{T}^{*}=\left[\mathrm{r}_{1}\right] /\left[4 \mathrm{r}_{2}\right]$

There exists equilibria $E_{1}$ and $E_{2}$ if 
Proof: There exists no Nash equilibrium in pure strategies if the $\phi(\mathrm{T})$ lies completely above the 45 degree line. This happens only when the minimum point $\phi\left(T^{*}\right)>T^{*}$. When this inequality is reversed, the function $\phi(T)$ intersects the 45 degree line at $E_{1}$ and $E_{2}$. We know $E_{2}$ is always unstable while $E_{1}$ is stable if (10a) holds. QED.

Observation 2: Note that even if $E_{1}$ is a stable equilibrium, changes in parameters can make $\mathrm{E}_{1}$ lose its stability. As an example consider the equilibrium $\mathrm{T}^{\mathrm{E}}$ that satisfies $(10 \mathrm{~d}) . \mathrm{T}^{\mathrm{E}}$ is thus a stable equilibrium if $\mathrm{T}^{\mathrm{E}}>\left[\mathrm{r}_{1}+2 \alpha_{1} \mathrm{Y}\right] /\left[4 \mathrm{r}_{2}\right]$. Now, if $\mathrm{a}_{1}$ increases, ceteris paribus and $\mathrm{T}^{\mathrm{E}}$ changes to $\mathrm{T}^{\mathrm{EE}}$ and if $\mathrm{T}^{\mathrm{EE}}<\left[\mathrm{r}_{1}+2 \mathrm{a}_{1} \mathrm{Y}\right] /\left[4 \mathrm{r}_{2}\right]$, bot the equilibria $\mathrm{E}_{1}$ and $\mathrm{E}_{2}$ become unstable.

Fiscal equilibrium and lessons from local governance in developed nations: The decentralization theorem of Oates (1972) suggests that local governments in advanced nations are effective in balancing the preferences and cost and, thereby, achieving a mix of local goods that efficiently satisfies the local demand. However, such an effective allocation may be blocked by interest group influence (Borge et al., 1995, Borge, 1993) that may lead to inefficiency in allocation even in advanced nations. It is quite likely that conflicting interests can block an efficient allocation of public goods in developing nations (Woodland and Kemp, 2002; Gangopadhyay, 2000 for the theoretical foundation).

The median voter model posits that local goods are supplied through a majority rule voting process. As a result, the supply response of a local government coincides with the preferences of the median voter (Rubinfeld, 1987; Bowen, 1943; Downs, 1957). Such a notion is inconsistent with a local government that provides many local goods and is influenced by powerful political parties (Borge et al., 1995). In such a scenario different groups of voters struggle to enforce their influences on local government (Craig and Inman, 1985; Renaud and van Winden, 1991). As a result, the paradigm of direct democracy has severe limitations in explaining the supply responses by local governments even in advanced industrial nations. The median-voter model may have very limited applicability in developing nations.

In the context of advanced industrial nations the (Tiebout, 1956) hypothesis provides the theoretical underpinning of efficient local expenditure. This hypothesis invokes the "invisible hand" principle to solve the public goods problem as posed by Samuelson (1954). The precise import of the hypothesis relies on the competitive market fable: profit maximizing local governments offering tax-local goods package come into economic contact with utility-maximizing residents who "vote with their feet". This interaction engenders usual forces of equilibration that effectively guide allocation of resources towards a Pareto-efficient outcome if local governments maximize their land values. Despite serious criticisms by Bewley (1981), the Tiebout hypothesis remains a "challenging reference" for advanced nations. In developing nations the lack of mobility of residents causes market failure as the residents do not "vote with their feet". The Tiebout hypothesis has been less tenable in developing nations also due to an absence of competition between local governments.

The main result is three-fold: first, the proposed fiscal game may not have a pure strategy Nash equilibrium. Secondly, when such equilibrium exists, it may not be unique. Finally, there may not exist a stable equilibrium. The message for a fiscal reform game is an intrinsic instability driven by some kind of coordination failure. More importantly, the possibility of multiple equilibria lifts the lid off the Pandora's box: a momentary departure from an equilibrium, or a minor perturbation in expectations, can have a lasting influence on the fiscal equilibrium. Also the multiplicity of equilibrium causes the standard problem of indeterminacy. The multiplicity of equilibria makes the political system extremely fragile that can have serious consequences for the local economy (Woodland and Kemp, 2002). Consider Diagram 2. History determines whether the stable equilibrium $\mathrm{E}_{1}$ gets established. If the initial value of $\mathrm{T}$ is contained within $E_{2}$, then the system steadily converges to $E_{1}$. Otherwise, the system fails to converge to any equilibrium outcome. Expectations play a crucial role in determining the equilibrium outcome. If all agents expect $E_{1}$ to be established, then $\mathrm{E}_{1}$ gets established. On the other hand, if all agents expect $E_{2}$ to get established, then the system reaches the unstable equilibrium $E_{2}$. Minor and momentary right-ward departure from $\mathrm{E}_{2}$-say, due to an increase in corruption-destabilizes the entire system. Greater instability is expected if both these equilibria $E_{1}$ and $E_{1}$ are unstable. A momentary departure from the equilibrium can trigger serious crisis as the system fails to reach a stable outcome. In this case the system is beset with unstable equilibria and the consequent fragility and instability. Even making sufficient resources available to the local government may thus fail to deliver "the good" since the system will fail to reach a stable equilibrium. Even when the initial equilibrium is stable, slight changes in parameters can render the equilibrium unstable and thereby lend fragility to the system. In the next we examine the possibility of chaotic dynamics that can characterize the equilibrium outcome of the proposed fiscal game. 
Dynamics of decision-making, fiscal equilibrium and chaotic regimes: We now consider the question of reaching the Nash equilibrium by economic actors when they make decisions in actual time. In this context chaos theory offers a new method in examining nonlinear dynamics, which we will apply in examining the dynamic properties of the fiscal equilibrium. Most of the applications of nonlinear dynamics in economics centre on modeling growth and business cycles in macroeconomics (Grandmont, 1986). Early models of chaos theory were developed by (Rand, 1978; Dana and Montruchhio, 1986) in the context of oligopoly, but these models remained very esoteric in terms of their economic imports. Ours is an attempt to show how chaos theory can be useful in understanding decisionmaking in public economics, especially in the context of local governance in developing nations. Chaos is viewed as a fully deterministic behavior pattern that is indistinguishable from a random process, or a process that is perturbed by substantial random elements (Gangopadhyay, 2005). To put it baldly, the precise contribution of chaos theory is to establish that even a simple dynamic system can generate seemingly random, complex and chaotic patterns over time. Thus, irregular and unpredictable time paths derive from deterministic sources (Brock and Rattso, 1993). It displays an extreme sensitivity to changes in the parametric values and is characterized by an infinite number of equilibria each approached by cycles of different periodicities in Woodford (1990).

Simple approximation and complex dynamics: We follow the method developed by Benhabib and Day (1980) to show how the dynamics of fiscal reforms can give rise to chaos. In this part we start off with the finding that the reaction function of the central government is given by (8a) while the local government responds as per Eq. $4 \mathrm{a}$.

$\theta=1 / 2-\left[c+a_{2} T(Y-T)\right]\left[a_{1} Y(Y-T)\right]$

The reaction function of the central government is:

$\mathrm{T}=[\mathrm{K} \theta-(1-\theta) \mathrm{Y}] /[2 \theta]$

We know $\mathrm{T}$ is the choice variable of the central government and $\theta$ is the choice variable of its rival, that is, the local government. We know the slope of the reaction function of the central government is:

$[\mathrm{dT} / \mathrm{d} \theta]_{\mathrm{CG}}=\mathrm{Y} /(2 \theta)^{2}$

Step 1: We make a simplification by assuming the central government (hereafter, CG) responds by a simple linear feedback rule:
$\mathrm{T}=\mathrm{k} \theta+\Psi$

(11b) is a linear version of (8a). We derive the composite reaction function of the local government (hereafter, LG) as:

$\mathrm{R}_{\mathrm{LG}}(\mathrm{t}+1)=\mathrm{RL}_{\mathrm{G}}(\mathrm{T}(\mathrm{t}+1))=\mathrm{R}_{\mathrm{LG}}(\mathrm{k} \theta+\Psi)$

The composed reaction function of the $L G$ is derived as:

$\theta(\mathrm{t}+1)=\mathrm{f}(\theta(\mathrm{t}))=[1 / 2]-\left[\mathrm{c}+\mathrm{A}_{2}(\Psi+\mathrm{k} \theta(\mathrm{t})(\mathrm{Y}-\Psi-\mathrm{k} \theta) \mathrm{t})\right] /$

$\left[\mathrm{A}_{1} \mathrm{Y}(\mathrm{Y}-\Psi-\mathrm{k} \theta(\mathrm{t}))\right]$

Successive substitutions lead to:

$\theta(\mathrm{t}+1)=\mathrm{f}(\theta(\mathrm{t}))=\left[\mathrm{h}_{0}-\mathrm{h}_{1} \theta(\mathrm{t})+\mathrm{h}_{2}(\theta(\mathrm{t}))^{2}\right] /\left[\mathrm{h}_{3}-\mathrm{h}_{4} \theta(\mathrm{t})\right]$

Where:

$\mathrm{h}_{0}=(1 / 2) \mathrm{a}_{1} \mathrm{Y}(\mathrm{Y}-\Psi)-\mathrm{c}-\mathrm{a}_{2}(\mathrm{Y}-\Psi)+\Psi$

$\left.\mathrm{h}_{1}=-(1 / 2) \mathrm{a}_{1} \mathrm{Yk} \theta(\mathrm{t})+\right) \mathrm{a}_{2} \mathrm{k}(1+\mathrm{Y})$

$\mathrm{h}_{2}=\mathrm{k}^{2} \mathrm{a}_{2}$

$\mathrm{h}_{3}==\mathrm{a}_{1} \mathrm{Y}(\mathrm{Y}-\Psi)$

$\mathrm{h}_{4}=\mathrm{a}_{1} \mathrm{Ky}$

Note that (11d) gives the time profile of $\theta$.

Step 2: The slope of the time profile of $\theta$ is:

$\mathrm{d} \theta(\mathrm{t}+1) / \mathrm{d} \theta(\mathrm{t})=\left[\mathrm{H}_{1}\right] /\left[\mathrm{H}_{2}{ }^{2}\right]$

Where:

$\mathrm{H}_{1}=\mathrm{h}_{0} \mathrm{~h}_{4}+2 \mathrm{~h}_{1} \mathrm{~h}_{3} \theta(\mathrm{t})-\mathrm{h}_{4}\left(2 \mathrm{~h}_{1}-\mathrm{h}_{2}\right)(\theta(\mathrm{t}))^{2}$

$\mathrm{H}_{2}=\left(\mathrm{h}_{3}-\mathrm{h}_{4} \theta(\mathrm{t})\right)^{2}$

For the hill-shaped $f(\theta(t+1))$ we just need:

$\mathrm{h}_{1}>\mathrm{h}_{2}$

Step 3: In this step we find out $\theta^{*}$ such that:

$d \theta(t+1) / d \theta(t)=F^{\prime}(\theta(t))=0$

Differentiating (11d) with respect to $\theta(t)$ yields: 
$\theta * a+b^{1 / 2}$

Where:

$\mathrm{a}=\left[\mathrm{h}_{1} \mathrm{~h}_{3}\right] /\left[\mathrm{h}_{4}\left(2 \mathrm{~h}_{1}-\mathrm{h}_{2}\right)\right]$

$\mathrm{b}^{1 / 2}=\left[\operatorname{Sqrt}\left\{\mathrm{h}_{1}{ }^{2} \mathrm{~h}_{3}{ }^{2}+\mathrm{h}_{4}\left(2 \mathrm{~h}_{1}-\mathrm{h}_{2}\right)\right\}\right] /\left[\mathrm{h}_{4}\left(2 \mathrm{~h}_{1}-\mathrm{h}_{2}\right)\right]$

Step 4: We now determine $\theta_{\mathrm{C}^{\circ}}$ such that:

$$
\begin{aligned}
& \mathrm{f}\left(\theta_{\mathrm{C}^{\circ}}\right)=a+b^{1 / 2}=\theta^{*} \\
& \text { or, } \left.\theta^{*}=\left[\mathrm{h}_{0}-\mathrm{h}_{1} \theta(\mathrm{t})+\mathrm{h}_{2}(\theta(\mathrm{t}))^{2}\right] /\left[\mathrm{h}_{3}-\mathrm{h}_{4} \theta(\mathrm{t})\right](\mathrm{Y}-\Psi-\mathrm{k} \theta(\mathrm{t}))\right]
\end{aligned}
$$$$
\text { Hence, }{ }^{\operatorname{Min}}\left\{\theta_{\mathrm{C}}{ }^{0}\right\}=\operatorname{Min}\left\{\left[\left(\mathrm{h}_{1}-\mathrm{h}_{4} \theta^{*}\right) \theta\right.\right. \text { SQRT: }
$$$$
\left.\left.\left.\left.\left\{\left(\mathrm{h}_{1}-\mathrm{h}_{4} \theta^{*}\right)^{2}-4 \mathrm{~h}_{2}\left(\mathrm{~h}_{0}-\mathrm{h}_{3} \theta^{*}\right)\right\}\right] /\left(2 \mathrm{~h}_{2}\right)\right\}=\right)\right\}=\theta^{\mathrm{C}}
$$

Step 5: Define $\theta^{\mathrm{m}}$ such that:

$$
\theta^{\mathrm{m}}=\mathrm{f}\left(\theta^{*}\right)=\mathrm{f}\left(\theta^{*}=\mathrm{a}+\mathrm{b}^{1 / 2}\right)
$$

Observation 3: The condition for chaotic regime is given by the Li-York theorem that requires:

$\mathrm{f}\left(\theta^{\mathrm{m}}\right)<\theta^{\mathrm{C}}<\theta^{*}<\theta^{\mathrm{m}}$

Observation 4: The condition for Li-York's theorem is satisfied if:

$\theta^{*}<\theta^{\mathrm{m}}$

$f\left(\theta^{\mathrm{m}}\right)<\theta^{\mathrm{C}}$

Note that (16c) holds if:

$\mathrm{M}=\mathrm{h}_{0}+\left(\mathrm{h}_{4}-\mathrm{h}_{2}\right)\left(\theta^{*}\right)^{2}-\theta^{*}\left(\mathrm{~h}_{1}+\mathrm{h}_{3}\right)>0$

(16c') holds if:

$\mathrm{N}=\left(\mathrm{h}_{0}-\mathrm{h}_{3} \theta^{\mathrm{C}}\right)-\left(\mathrm{h}_{1}-\mathrm{h}_{4} \theta^{\mathrm{C}}\right) \theta^{\mathrm{m}}+\left(\theta^{\mathrm{m}}\right)^{2} \mathrm{~h}_{2}>0$

Observation 5: It can be shown that the sufficient condition for (A1) to be true is:

$\theta^{\operatorname{Min}}<\theta^{*}<\theta^{\operatorname{Max}}$

Where:

$$
\begin{aligned}
\theta^{\mathrm{Min}}= & {\left.\left[\left(\mathrm{h}_{1}+\mathrm{h}_{3}\right)-\mathrm{SQRT}\left\{\mathrm{h}_{1}+\mathrm{h}_{3}\right)^{2}-4 \mathrm{~h}_{0}\left(\mathrm{~h}_{4}-\mathrm{h}_{2}\right)\right\}\right] / } \\
& {\left[2\left(\mathrm{~h}_{4}-\mathrm{h}_{2}\right)\right] }
\end{aligned}
$$

$$
\begin{aligned}
& \left.\theta^{\mathrm{Max}}=\left[\left(\mathrm{h}_{1}+\mathrm{h}_{3}\right)+\operatorname{SQRT}\left\{\mathrm{h}_{1}+\mathrm{h}_{3}\right)^{2}-4 \mathrm{~h}_{0}\left(\mathrm{~h}_{4}-\mathrm{h}_{2}\right)\right\}\right] / \\
& {\left[2\left(\mathrm{~h}_{4}-\mathrm{h}_{2}\right)\right]}
\end{aligned}
$$

Observation 6: It can be established that the sufficient condition for the inequality (A2) to hold we need:

$\left[\mathrm{h}_{1} / \mathrm{h}_{4}\right]<\theta^{\mathrm{C}}<\left[\mathrm{h}_{0} / \mathrm{h}_{3}\right]$

Discussion of the results and some promises: The purpose of these results is to make policy makers aware of the complex nature of the local government system that has evolved in developing nations due to historical and social reasons. In our understanding, the role of the policy maker is to master the relevant economic system to be able to adopt appropriate actions now that will lead to desirable outcomes, or will help avoid undesirable outcomes, in the future. The policy maker must be able to predict the outcome of current activities while the ability of so doing is predicated upon an understanding of the relevant economic system. These models should help the rational policy maker to understand the difficult attributes of the local government system in developing nations. What we purport is three-fold: First and foremost, a small change in the local government parameters can lead to major transformation of the system - this is what is known as "chaos" if we confine our attention to mathematical, or physical, systems. Political scientists use a phrase "crisis instability" to describe this extreme sensitivity of the political system to minor perturbations (Gangopadhyay, 2007; 2005; Saperstein, 1984). Secondly, we show the possibility that the local government system in a developing nation as modeled can display remarkable stability in some circumstances driven by the values of relevant parameters. For a social system the importance of this stability is wellunderstood as in (Saperstein, 1984). We showed how history, or expectations, can determine whether a stable equilibrium, $\mathrm{E}_{1}$, gets established. The local government system can display complex behavior if the system fails to converge to any equilibrium outcome. In our model minor and momentary right-ward departure from $E_{2}$ destabilizes the entire system. Serious instability can also be created by purely subjective factors. The switch from stability to chaos can also be triggered by bifurcation properties of equilibrium $E_{1}$. The switch to chaos can be triggered by the emergence of the chaotic regimesconditions for which are detailed in the paper..

From (Saperstein, 1984) we know that a chaotic economic system is a mathematical representation of a crisis-ridden and unstable economic system. Policy makers therefore must take extreme caution in tweaking with the system. For policy making it is important to 


\section{J. Math. \& Stat., 7 (3): 239-248, 2011}

predict the critical threshold beyond which the local government system becomes chaotic. For the policy maker it will be important to avoid conditions, or circumstances, that will throw the system into crisis and instability. Finally, the model clearly demarcate a region of stability $\left(0, \mathrm{E}_{2}\right)$ vis-à-vis a region of instability (beyond $\mathrm{E}_{2}$ ) in Diagram 2. Our argument is similar to the "edge of chaos theory". Stacey (1991) adopted the concept of "edge of chaos theory" for social sciences to argue that sustainability of a social system is achieved by the relevant decision-makers striving to remain at the confluence of the predictable "order" (the interval $\left[0, \mathrm{E}_{2}\right]$ in Diagram 2) and an unpredictable level of chaos (beyond $E_{2}$ in Diagram 2). Chambers (1997) employed this concept of edge of chaos to explain the sustainability of rural communities in developing nations. Ours is a first attempt to provide a model that can be strained to explain the sustainability of local governments in developing nations.

\section{MATERIALS AND METHODS}

Local governments must have reasonable autonomy in determining local taxes and local goods. This is necessary for making local governments accountable. The art of local governance is a delicate balancing act: Autonomy and accountability will allow a local government to vary local taxes to collect larger revenues to finance higher levels of local services, if the local government so chooses. This would allow the local government to establish a linkage between revenues and expenditure. Local revenues ought to be collected from local residents in proportion to perceived benefits of local residents from local services. Such decentralization leads to fiscal disequalization as richer zones will collect more revenues. In order to offset this disequalization, intergovernmental transfers are designed to endow local governments with sufficient revenues to provide a "standard" level of local expenditure. Sensible local governance is thus built on fiscal autonomy and accountability of local governments along with appropriately designed transfers. Against this backdrop, we argue that incorrect designs of transfers; and a lack of true accountability and corrupt behavior can cause serious distortions in the provision of local goods in developing nations.

\section{RESULTS}

We developed a simple fiscal game involving local and central governments to characterize potential (Nash) equilibrium outcomes in the provision of local goods. In the proposed model, the fiscal setting is grounded on the historical peculiarities of the local governance inherited from the colonial pasts of developing nations. We find that the proposed game is beset with indeterminacy due to the multiplicity of the Nash equilibrium. We noted that the equilibrium can be Pareto ranked. The equilibrium with a high level of local taxes is shown to be always unstable. The equilibrium with a low level of local taxes is stable only if a condition is satisfied. If this condition does not hold, the fiscal game does not have a stable equilibrium. It is also shown that the fiscal game may not have a pure-strategy Nash equilibrium. The lack of a stable equilibrium and an absence of pure-strategy Nash equilibrium render the equilibrium of the fiscal game highly fragile. Even when the equilibrium is stable, we showed that the equilibrium can lose stability and exhibit serious bifurcation properties with small changes in the values of relevant parameters. The bifurcation possibility adds further instability and fragility to local governments.

\section{DISCUSSION}

We offered a detailed dynamic analysis to address the attainability of one of the equilibria of the fiscal game. The analysis of the dynamics of decision-making in the fiscal milieu of developing nations establishes the possibility that the dynamical system is characterized by significant nonlinearities and beset with chaotic regimes. The development of chaotic behavior significantly undermines the dismissal of regions of instability that can actually generate complex, yet deterministic, dynamics within bounds. By so doing we are able to highlight the importance of chaotic behavior in the context of urban local governance in developing nations. Public finance and urban economists typically focus their attention on economic models with regions of local stability on the implicit assumption that regions of instability are of little importance and more of a pathological case. Ours is an attempt to demonstrate how nonlinearities and chaotic regimes can play an important role in causing local government failure in developing nations.

Philosophically speaking, the proposed model also makes an important theoretical departure. The finding has important bearings: it is typically assumed in the deductive equilibrium approach to modern economic theory that the Nash equilibrium dispels all systematic prediction errors and the economic system settles in an equilibrium characterized by self-confirming and mutual-best responses. This approach has a strong influence upon modern public finance and urban economics. The deductive equilibrium analysis has 
significantly aided our collective understanding of local governance, especially in developed nations. However, little attention has been given to the regions of instability, which may be of great significance of local governance in developing nations. We establish that the postulated dynamics of fiscal decision-making can exhibit chaotic behavior: Relevant players (governments at different levels) now fail to see systematic errors. Governments also fail to make longrun predictions with certainty even though they act in a deterministic world. Time profiles, which start very close together, will separate exponentially. The strength of static Nash equilibrium gets terribly emasculated.

\section{CONCLUSION}

Policy implications are three-fold. First of all, it is necessary to stamp corruption out of the local governance. Secondly, it is imperative to revamp local tax systems so that residents pay a decent price for a decent service and also ensure minimum resources be spent on these local goods. Finally, in consonance with the era of decentralization and deregulation, we suggest that it may be necessary to introduce Tiebout type of competitive forces in providing local goods in order to redress local government failure in developing nations. Local tax reforms and forces of competition are necessary to break the electoral equilibrium that taxes little and provides little of local goods.

\section{ACKNOWLEDGEMENT}

The study is supported by the School of Economics and Finance, University of Western Sydney, NSW, Australia.

\section{REFRENCES}

Benhabib, J. and R.H. Day, 1980 Erratic accumulation Econ. Lett., 6: 113-117. DOI: 10.1016/01651765(80)90067-1

Bewley, T., 1981. A critique of tiebout's theory of local public expenditure. Econometrica, 49: 713-740. DOI: $10.2307 / 1911519$

Bird, R.M. and C. Wallich, 1992. Financing Local Government in Hungary. 1st Edn., Country Economics Dept., Washington, pp: 87.

Bird, R.M., 1993. Threading the Fiscal Labyrinth: Some Issues in Fiscal Decentralization. Nat Tax J., 46: 207-207. http://direct.bl.uk/bld/PlaceOrder.do?UIN=008999 $624 \&$ ETOC $=$ EN\&from=searchengine
Bird, R.M., 1995. Financing Local Services: Patterns, Problems and Possibilities. University of Toronto. http://www.citiescentre.utoronto.ca/Assets/Cities+ Centre+Digital+Assets/pdfs/publications/Major+R eport+Series/MR31+Bird+1995+Financing+Local + Services.pdf

Bird, R.M., J.L. Litvack and M.G. Rao, 1995. Intergovernmental Fiscal Relations and Poverty Alleviation in Viet Nam. 1st Edn., World Bank, Washington, D.C., pp: 48.

Borge, L. and J. Rattso, 1993. Dynamic responses to changing demand: a model of the reallocation process in small and large municipalities in Norway. Applied Econ., 25: 589-598. DOI: 10.1080/00036849300000003

Borge, L., J. Rattso and R. Sorensen, 1995. Local government service production: The politics of allocative sluggishness. Public Choice, 82: 135-157. DOI: 10.1007/BF01047734

Bowen, H.R.,1943. The interpretation of voting in the allocation of economic resources. Quar. J. Econ., 58: 27-48. DOI: $10.2307 / 1885754$

Brock, W.A., 1993. Pathways to randomness in the economy: Emergent nonlinearity and chaos in economics and finance. Estudios Econ., 8: 3-55. http://www.jstor.org/pss/40311322

Chambers, R., 1997. Whose Reality Counts? Putting the First Last. 2nd End., Intermediat Technology, London. ISBN: 185339386X, pp: 297.

Craig, S. and R.P. Inman, 1985. Education, Welfare and the New Federalism: State Budgeting in a Federalist Public Economy. In: Studies in the State and Local Public Finance, Rosen, H., (Ed.)., University of Chicago Press, Chicago, ISBN: 0226726215, pp: 187-227.

Dana, R.A. and L. Montruchhio, 1986. Dynamic complexity in duopoly games, J. Econ. Theory, 40: 40-56. DOI: 10.1016/0022-0531(86)90006-2

Downs, A., 1957. An Economic Theory of Democracy. 1st Edn., Harper, New York, pp: 310.

Gangopadhyay, P. and S. Nath, 2001a. Bargaining, coalitions and local expenditure. Urban Stud., 38: 2379-2391. DOI: 10.1080/00420980120094560

Gangopadhyay, P. and S. Nath, 2001b. Deprivation and incidence of urban public services: A tale of three cities. Rev. Urban Regional Dev. Stud., 13: 207-220. DOI: 10.1111/1467-940X.00041

Gangopadhyay, P., 2000. On the coase theorem and coalitional stability: The principle of equal relative concession. Theory Decis., 48: 179-191. DOI: 10.1023/A:1005142606780 
Gangopadhyay, P., 2005. Chaotic discrimination and non-linear dynamics. Am. J. Applied Sci., 2: 441449. DOI:10.3844/ajassp.2005.441.449

Gangopadhyay, P., 2007. Competitive tax evasion and transfer prices. Int. Game Theory Rev., 9: 347-351 DOI: $10.1142 /$ S0219198907001448

Grandmont, J.M., 1986. Nonlinear Economic Dynamics. 5th Edn., Academic Press, Boston, ISBN: 0122951409, pp: 195.

Oates, W., 1972. Fiscal Federalism. 1st Edn., Harcourt Brace Javanovich, New York, ISBN: 015527452X, pp: 256.

Rand, D., 1978. Exotic phenomena in games and duopoly models. J. Math. Econ., 5: 173-184. DOI: 10.1016/0304-4068(78)90022-8

Renaud, P. and F. van Winden, 1991. Behavior and budgetary autonomy of local governments: A multi-level model applied to the netherlands, Eur. J. Polit. Econ., 7: 547-577. DOI: 10.1016/01762680(91)90036-3

Rubinfeld, D., 1987. The Economics of Local Public Sector. In: Handbook of Public Economics, Feldstein, M. and A. Auerbach, (Eds.)., NorthHolland, Amsterdam, ISBN-10: 0444879080, pp: 571-645.
Samuelson, P.A., 1954. The pure theory of public expenditure. Rev. Econ. Statist, 36: 387-389. DOI: $10.2307 / 1925895$

Saperstein, A.M., 1984. Chaos-a model for the outbreak of war. Nature, 309: 303-05. DOI: 10.1038/309303A0.

Shah, A., 1991. Perspective on the Design of Intergovernmental Relations. 1st Edn., Country Economics Dept., Washington, pp: 107.

Stacey, R.D., 1991. The Chaos Frontier: Creative Strategic Control for Business. 1st Edn., Butterworth-Heinmann, Oxford, ISBN: 0750601396, pp: 409.

Tiebout, C., 1956. A pure theory of local expenditure. J. Polit. Econ., 64: 416-424. DOI: 10.1086/257839

Woodford, M., 1990. Equilibrium Models of Endogenous Fluctuations: An Introduction. 1st Edn., National Bureau of Economic Research, Cambridge, pp: 50.

Woodland, A. and M.C. Kemp, 2002. Economic Theory and International Trade: Essays in Honour of Murray C. Kemp. $1^{\text {st }}$ Edn., Edward Elgar, Cheltenham, ISBN: 1840642947, pp: 329. 